\title{
AÇÕES ANTRÓPICAS E O ADVENTO DAS CIÊNCIAS AMBIENTAIS
}

\author{
Genesio Mario da Rosa ${ }^{1}$ \\ Caroline Emiliano Santos ${ }^{2}$ \\ Daniela Sartor ${ }^{3}$ \\ Debora Seben ${ }^{4}$ \\ Giuvana Lazzaretti ${ }^{5}$
}

\begin{abstract}
Resumo: As Ciências Ambientais abrangem a interação entre o ser humano e as questões bióticas e abióticas que os rodeiam. O presente artigo tem por objetivo interrelacionar os subtemas ações antrópicas, Ciências Ambientais, Educação Ambiental, desenvolvimento sustentável e interdisciplinaridade, dentro do tema central Ciências Ambientais, através de uma discussão fundamentada em pesquisa empírica de abordagem qualitativa. Dessa pode-se inferir que com a evolução da espécie humana, a exploração e o consumo passaram de sobrevivência/subsistência para consumo desenfreado. As Ciências Ambientais como tema interdisciplinar, emerge nesse cenário, a fim de melhorar o conhecimento técnico científico e, por consequência, a sociedade.
\end{abstract}

Palavras-Chave: Ciências Ambientais. Educação Ambiental, Ações antrópicas, Interdisciplinaridade.

Abstract: Environmental Sciences cover the interaction between human beings and the biotic and abiotic issues that surround them. This article aims to interrelate the subthemes anthropic actions, Environmental Sciences, Environmental Education, sustainable development and interdisciplinarity, within the central theme Environmental Sciences, through a discussion based on empirical research with a qualitative approach. From this it can be inferred that with the evolution of the human species, exploration and consumption changed from survival/subsistence to rampant consumption. Environmental Sciences as an interdisciplinary theme, emerges in this scenario, in order to improve scientific technical knowledge and, consequently, society.

Keywords: Environmental Sciences. Environmental education, Anthropic actions, Interdisciplinarity.

\footnotetext{
1 Universidade Federal de Santa Maria. E-mail: genesiomario@yahoo.com.br, Link para o Lattes: http://lattes.cnpq.br/6868821306663236

2 Universidade Federal de Santa Maria. E-mail: caroline_emiliano@hotmail.com. Link para o Lattes: http://lattes.cnpq.br/8898286172331521

3 Universidade Federal de Santa Maria. E-mail: daniela_sartor@hotmail.com. Link para o Lattes: http://lattes.cnpq.br/0472179105617192

${ }^{4}$ Universidade Federal de Santa Maria. E-mail: debyseben@hotmail.com.

Link para o Lattes: http://lattes.cnpq.br/6843721634145750

${ }^{5}$ Universidade Federal de Santa Maria. E-mail: giuvanalazzaretti@hotmail.com. Link para o Lattes: http://lattes.cnpq.br/3545677408271739
} 


\section{Introdução}

O aumento populacional, aliado ao aumento do uso dos recursos naturais, a maior demanda por alimentos e a maior geração de resíduos, resultaram nas últimas décadas em uma crescente preocupação em relação aos impactos antrópicos pelo uso indiscriminado dos recursos naturais. Esse processo é notadamente sentido, quando se observa a expansão das áreas urbanas, das obras civis, do aumento das atividades agropecuárias, entre outras, as quais trazem problemas relacionados a desmoronamentos, assoreamento dos corpos hídricos, degradação dos solos, gerando impactos ambientais negativos (GUERRA; MARÇAL, 2010).

Além do uso indiscriminado dos recursos naturais, o consumo em larga escala e o desenvolvimento tecnológico traz à tona o modelo econômico capitalista, hegemônico na maioria dos países do globo terrestre, que em nome de um propagado desenvolvimento econômico provoca desequilíbrios de diversas escalas na natureza. Toda e qualquer forma de ação antrópica realizada para fins de subsistência e ou desenvolvimento humano acarretam alguma forma de impacto e desequilíbrio ambiental (DA ROSA et al., 2020). Segundo Altvater (1995) esse desequilíbrio pode ser comprovado quando $42 \%$ de toda energia produzida no mundo é consumida por menos de $12 \%$ da população mundial. Os efeitos desse desequilíbrio ficaram evidentes e podem ser comprovados pelas estimativas da OMS (2014) que afirma, que no ano de 2012 cerca de 7 milhões de pessoas morreram, uma em cada oito do total de mortes globais, como resultado da exposição à poluição do ar advinda de processos industriais.

Nesse sentido, devido a esse processo de segregação e a não interação do homem com o meio ambiente, apresentando assim um vazio entre o desenvolvimento científico e o tecnológico, afirma Rohde (1996) que as Ciências Ambientais surgem nesse cenário para preencher esse espaço, pois até então nenhuma ciência tinha sido capaz de desenvolver conhecimentos suficientes para integrar tais questões.

A inserção das Ciências Ambientais nesse contexto que aproxima o homem e o meio ambiente depende, inicialmente, da compreensão dos termos interdisciplinaridade, transdisciplinaridade e multidisciplinaridades que assumem diversos significados, mas mantém, em comum, a aproximação acadêmico-científica, essencial para que as produções científicas não fujam e, por outro lado, sirvam para as necessidades da sociedade. Seguindo essa lógica, de acordo com Alves (2004) é necessário acabar com o comportamento que inibe o pensamento da sociedade que, por outro lado, motivada principalmente pelo distanciamento entre a sociedade e a ciência, esses chegam a acreditar que o cientista é uma pessoa que pensa melhor do que as outras.

Nesse sentido, as discussões sobre as questões ambientais vêm ganhando destaque nos encontros internacionais, potencializando debates em 
relação ao meio ambiente, com o objetivo de moldar caminhos para o desenvolvimento sustentável.

$\mathrm{Na}$ busca desses caminhos, a efetiva interação entre a prática científico-tecnológica e o desenvolvimento social sustentável, são fundamentais para solucionar os problemas ambientais, de tal forma que a conexão entre o conhecimento proporcione atividades altamente sofisticadas e sustentáveis (WALGENBACH et al., 2000). Essa é uma visão de futuro alcançável, pois a sociedade tem o poder de criar e modificar sua cultura. Isso também ajudará o homem a perceber sua natureza biológica e sua relação com o meio ambiente e, dessa forma, não exceda as suas necessidades biológicas ao extrair da natureza os recursos naturais.

Para tanto, necessitamos de um olhar mais amplo para compreender estas relações, e as Ciências Ambientais colaboram com essa visão, pois permite transitar por um ambiente interdisciplinar, uma vez que segundo Santana et al. (2017) a disciplinarização é apontada como uma das maiores causas das problemáticas do não entendimento das questões ambientais, pois estruturou um desenvolvimento tecnológico sem preocupação com o ambiente.

Nessa abordagem, o presente artigo busca contextualizar a temática do homem inserido nas Ciências Ambientais e sua abordagem multidisciplinar, tendo por objetivo analisar a literatura acerca do tema, com o intuito de promover a compreensão sobre as Ciências Ambientais.

\section{Metodologia}

O presente estudo é essencialmente baseado em pesquisa bibliográfica sobre os temas aqui inter-relacionados ás Ciências Ambientais, através de uma profunda revisão bibliográfica referente ao assunto descrevendo suas bases conceituais, as mudanças apresentadas ao longo do tempo e sua perspectiva atual. Para tanto, a partir da definição das temáticas e descritores, entre eles ações antrópicas, Ciências Ambientais, Educação Ambiental, desenvolvimento sustentável e interdisciplinaridade no decorrer do semestre do ano de 2020 e primeiro de 2021, se deu a seleção de leituras de estudos científicos como artigos científicos, livros e legislação brasileira em relação aos temas abordados. Como base de dados para consulta usou-se a plataforma do Google Scholar para acesso aos artigos científicos disponíveis de forma digital.

O texto utiliza-se de uma abordagem qualitativa sobre o objeto, ou seja, busca refletir sobre as questões que envolvem o tema Ciências Ambientais, articulando bases empíricas, conceitos e reflexões teóricas e intersubjetivas, conduzindo a interfaces e possibilidades na temática e abordagem, como contribuição de análise reflexiva. Nesse sentido e levando-se em conta as contribuições de Minayo (2002) a pesquisa qualitativa abrange a capacidade de responder a questões particulares, assim, podendo trabalhar com sentidos e significados, crenças, atitudes, valores, aspirações e motivações, adentrando 
nos campos dos processos, relações e fenômenos que não podem ser medidos de maneira quantificável e através de variáveis. Assim, da análise textual utilizada nas informações vincula-se à análise interpretativa (SEVERINO, 2013), onde objetivou-se sintetizar as ideias e concepções para compreensão das informações textuais (etapa da análise e interpretação). Por meio da interpretação e associação das ideias expostas nas bibliografias, elaborou-se a análise interpretativa e crítica, na qual se apresenta um posicionamento frente às informações analisadas.

\section{Resultados e discussão}

\section{O surgimento das ciências ambientais}

Foi por volta da década de 60 e 70 que uma crise movida pelo fracionamento do conhecimento e a degradação ambiental, podendo ser comparada à crise de civilização e ao "logocentrismo da ciência moderna e o transbordamento da economia do mundo guiado pela racionalidade tecnológica e pelo livre mercado", que o ser humano percebeu que os recursos naturais são finitos (LEFF, 2008). Isso provocou, em última análise, a tomada de consciência dos problemas ambientais existentes, como por exemplo: a chuva ácida, aquecimento global e o buraco da camada de ozônio. A partir de então, todas as ciências voltaram-se para a relação homem versus natureza (MELARA; CARDOZO, 2017).

$\mathrm{Na}$ busca pelo entendimento das Ciências Ambientais compreendeu-se como um estudo da relação existente entre o ser humano e as questões bióticas e abióticas que os rodeia. Assim, as Ciências Ambientais integram o conhecimento das ciências naturais (como a biologia, geologia e química), as ciências sociais (como a economia, geografia e ciências políticas) e as ciências humanas (como a ética e filosofia) (MILLER, 2008).

Nessa perspectiva Miller (2008) afirma que as Ciências Ambientais possuem alguns objetivos, entre eles o de aprender como a vida na terra sobreviveu e prosperou, entender a interação do homem com o meio e encontrar maneiras de enfrentar os problemas ambientais e viver sustentavelmente. $\mathrm{O}$ autor afirma que as principais disciplinas das ciências se remetem à ecologia e às ciências biológicas, que estudam os organismos e a interação entre eles.

Da mesma forma, o foco da biologia são os ecossistemas, conjuntos de organismos que vivem em determinada área e interagem entre si e com o meio. Assim, em virtude da grande quantidade de atividades antrópicas que ocorrem na superfície terrestre, e essa ser constantemente modificada para atender às necessidades da população, a geomorfologia ambiental traz contribuições importantes para o entendimento das Ciências Ambientais (GIRÃO; CORREA, 2004). 
Dentro dessa visão, Alves (2004) afirma que a ciência permite construir uma ordem ainda invisível de uma desordem visível e imediata. Ao considerar esses fatores e a geração de novos conhecimentos percebesse que as Ciências Ambientais, foram introduzidas em um cenário interdisciplinar (PHILIPPI Jr. et al., 2000; GUERRA; MARÇAL, 2010).

Nesse sentido, e corroborando com a afirmação anterior, Rosa et al. (2021), ressaltam que há necessidade de se compreender em uma perspectiva interdisciplinar aspectos do contexto histórico de ocupação, a interferência antrópica e a exploração, que pode ser vista como uma questão potencialmente relevante para se pensar os espaços atuais, suas conformações e as relações estabelecidas, assim, produzindo explicações e compreensões que evidenciem elementos que podem não estar sendo considerados e que poderão se colocar em prejuízo.

É nesse contexto que na década de 90, conforme descrito por Philippi Jr. et al. (2000) que surge a área de Ciências Ambientais, como um subprograma das Ciências Tecnológicas e, que trouxe consigo o objetivo de inserir a dimensão ambiental no processo de desenvolvimento tecnológico, fazendo com que nele fosse incorporado também o conceito de sustentável.

Destaca-se aqui, que uma atividade sustentável é aquela que explora os recursos naturais, mas de maneira sustentável, evitando assim, seu esgotamento e a consequente preservação desses para as futuras gerações. Da mesma forma, o desenvolvimento sustentável é quando há melhoria na qualidade de vida das pessoas, ao mesmo tempo em que há respeito com os ecossistemas (MIKHAILOVA, 2004).

Porém, os significados destes termos variam na literatura em virtude do número de perspectivas e vinculações ao contexto e ao campo de atuação (STEPANYAN; LITTLEJOHN; MARGARYAN, 2013) e, por outro lado, mesmo que permaneça a ausência de consenso sobre o conceito destes termos, é notória à busca do equilíbrio entre as necessidades do ser humano e o meio ambiente e, no mesmo sentido, o entendimento de suas complexas dinâmicas de interação, para que se possa aprofundar e ampliar seu significado (BARBOSA; DRACH; CORBELLA, 2014).

\section{Ações antrópicas e o meio ambiente}

Estima-se que o surgimento da vida no Planeta Terra foi há cerca de 3,5 bilhões de anos. A partir de então, a natureza vem passando por significativas mudanças, desde o impacto provocado por meteoritos, a era do gelo e o período de aquecimento. O aparecimento da espécie humana (Homo sapiens sapiens) é apontado como tendo ocorrido há aproximadamente 200 mil anos, ou seja, um tempo muito inferior desde o aparecimento da vida na Terra (MILLER, 2008). 
A espécie humana sempre esteve em evolução. Desde seu surgimento na terra o homem tenta compreender o mundo a sua volta e, por outro lado, passou a transformar o meio ambiente para colocá-lo a seu serviço, resultando em uma relação exploratória do homem sobre a natureza para garantir sua sobrevivência, o que modifica cada vez mais o ambiente (ANTUNES, 2005).

A evolução da civilização e o sedentarismo tirou o homem do processo de ser nômade e, assim, dividir-se em equipes de caça (homens) e coletores (mulheres) para que habitassem fixamente uma região, passando assim a dominar a agricultura (UBALDO, et.al., 2019). Historicamente o ambiente em que o homem está inserido, foi modificado para a garantia de sua sobrevivência, tal fato, pode-se dizer que ocorria de forma harmônica.

Posterior a esse processo histórico, surgem os efeitos das atividades do homem no meio ambiente. Houve então o período da expansão colonial, agricultura moderna e, como consequência, a maciça degradação ambiental unida ao uso desordenado dos recursos naturais (DELARIVA; AGOSTINHO, 1999).

No princípio da humanidade, havia uma unicidade orgânica entre o homem e a natureza, onde o ritmo de trabalho e da vida dos homens associava-se ao ritmo da natureza. No contexto do modo de produção capitalista, este vínculo é rompido, pois a natureza, antes um meio de subsistência do homem, passa a integrar o conjunto dos meios de produção do qual o capital se beneficia (OLIVEIRA, 2002, p.5).

O ser humano na posição de domínio e pensando ser capaz de controlar, transformar e direcionar os recursos naturais produz problemas ambientais que, por vezes, são 'justificados' como necessidades (PASSOS; OLIVEIRA, 2016). Esses problemas ambientais são citados como: crise hídrica, mudanças climáticas, degradação da biodiversidade, geração de resíduos, entre outros. Além disso, há problemas sociais relacionados aos ambientais: inacessibilidade à saúde, educação, moradia, saneamento básico, empregos e baixa renda. Um exemplo disso é o descaso com alguns locais, os quais são em geral, ocupados por grupos de pessoas marginalizadas pela sociedade, resultando em precárias condições de moradia, higiene e alimentação (CIDREIRA-NETO; RODRIGUES, 2017).

Outro exemplo de vulnerabilidade e que possui estreita relação com riscos ambientais é o caso de construção de moradias localizadas em áreas com alta declividade, com possibilidade de deslizamentos e soterramentos de pessoas e/ou habitações em áreas sujeitas a enchentes e inundações (PASSOS; OLIVEIRA, 2016).

Por esse ângulo, a relação harmônica entre o homem e o meio, existente nos primórdios da civilização, foi substituída em função do capitalismo pela exploração e uso desenfreado dos recursos naturais, tendo como objetivo 
a obtenção de riquezas e desenvolvimento. Assim, a natureza passa a ser utilizada como um elemento infinito, passível de exploração para o desenvolvimento (LOPES, 2011), sem a preocupação com a preservação ou conservação do meio ambiente e dos recursos naturais.

Dessa análise percebe-se que com a evolução do homem, aliada a evolução das ciências e com elas o advento das tecnologias, que tem seu marco na revolução industrial, chegou-se a um ponto crítico do desenvolvimento exploratório dos recursos naturais.

Nessa ótica, no início dos anos 70 as discussões eram voltadas para a ideia de que o progresso tecnológico era a forma capaz de ultrapassar os limites do crescimento econômico e populacional. No entanto, esse crescimento tecnológico já deixava suas marcas e era visto como uma estratégia perigosa:

O otimismo tecnológico é a reação mais comum e mais perigosa às nossas descobertas a partir do modelo do mundo. A tecnologia pode amenizar os sintomas de um problema sem afetar as causas subjacentes (...) [e] pode, assim, desviar nossa atenção do problema mais fundamental: o problema do crescimento num sistema finito (MEADOWS et al., 1973, p 23).

Nesse mesmo contexto Meadows et al. (1973), também alertavam sobre os riscos que as tecnologias podem acarretar ao ambiente. Dentre esse risco cita, por exemplo, as tecnologias agrícolas voltadas para o aumento da produtividade das culturas, alertando que essas com o tempo, têm efeitos indesejáveis.

Nesse ponto em 1987, com a missão de propor uma agenda global para as mudanças climáticas, advindas principalmente, pelo incremento das tecnologias introduzidas aos processos produtivos, a ONU (Organização das Nações Unidas) através do Relatório Brundtland, definiu entre outras ações o conceito de sustentabilidade, sendo esse: "Desenvolvimento sustentável é aquele que atende as necessidades das gerações atuais sem comprometer a capacidade das gerações futuras de atenderem às suas necessidades e aspirações" (COMISSÃO MUNDIAL DE MEIO AMBIENTE E DESENVOLVIMENTO, 1987).

A sustentabilidade, por sua vez, pode ser entendida como as capacidades que os sistemas naturais do meio ambiente e cultural do homem, possuem para sobreviver às mudanças ambientais, desenvolvem-se e adaptam-se em longo prazo (ROOS; BECKER, 2012). No entanto, Miller (2008) acredita que para a sustentabilidade de longo prazo da vida neste planeta há três princípios baseados na ciência, que devem estar em equilíbrio: energia solar, biodiversidade e ciclagem química. 
A energia solar garante $o$ aquecimento do planeta e luz para a fotossíntese das plantas, sem ela a vida atual não existiria, pois não haveria plantas, em consequência, não haveria animais e, dessa forma, nenhum alimento para a vida humana. A biodiversidade representa a diversidade de espécies que habitam o planeta, os quais interagem e se adaptam com o meio e entre as espécies, proporcionando imensuráveis maneiras de adaptabilidade da vida, em meio às mudanças ambientais. A ciclagem química ou de nutrientes, assegura a sustentação da vida por meio de infinitos ciclos químicos, que devolvem para o ambiente nutrientes necessários para a vida (MILLER, 2008).

Porém, a exploração descontrolada dos recursos naturais a fim de obter ganhos monetários à curto prazo, maximizando uma atividade produtiva (LAYRARGUES, 2000) desde o início da humanidade até os dias atuais, faz com que a própria espécie humana desequilibre a forma sustentável de vida do planeta. E dessa forma, alterando a ciclagem química que depende da biodiversidade, e vice-versa, perdendo assim, o controle sobre o necessário equilíbrio sustentável (PEREIRA, 2009).

A partir da segunda metade do século passado, a humanidade acompanhou as consequências da Revolução Industrial, resultando na substituição da manufatura pela indústria mecânica, aumentando a produção e o avanço de novas tecnologias. Este episódio teve foco apenas na produtividade, com base no crescimento econômico e, não se preocupou com a qualidade do meio ambiente e a saúde da população. Tal fato resultou na contaminação dos rios, poluição do ar, vazamento de produtos químicos, entre outros fatores, alterando assim o modo de vida no planeta (POTT; ESTRELA, 2017).

Nesse sentido, o advento da industrialização trouxe novos processos produtivos, que objetivaram o desenvolvimento de produtos em larga escala. $O$ modelo de desenvolvimento segue sendo sustentado pelo crescimento demográfico e pelo modelo econômico capitalista, modelo este, adotado atualmente na maior parte dos países, fortalecendo assim, o consumo de bens e serviços, que na pluralidade das vezes, não carregam em si o conceito de sustentabilidade, tanto na manufatura, quanto como no uso, ou no gerenciamento de resíduos gerados ao final dos processos.

A adoção do processo produtivo em larga escala desencadeou um considerável crescimento da industrialização e da diversificação de produtos, no entanto, sem a devida preocupação com o meio ambiente natural. Tal fato refletiu-se na exploração de grandes extensões territoriais, resultando em problemas ambientais de grandes dimensões (LEAL; FARIAS; ARAUJO, 2008) como a modificação das paisagens por meio da agricultura industrial, da urbanização, da criação de animais de forma extensiva ou em confinamentos, da mineração e da pesca predatória (SANTOS, et. al., 2018). 
Tais mudanças causaram impactos negativos, tanto na ordem cultural e social, quanto econômica. As relações entre a natureza e a sociedade foram modificadas, passando a natureza a ter apenas a função de abrigar a produção de alimento e a extração de matérias primas para a produção de bens de consumo (CAVALCANTI et al., 1994). Essa visão extrativista resultou na destruição de grandes áreas em quase todos os ambientes naturais, levando inúmeras espécies tanto da fauna como da flora à extinção ou ao risco de extinção (SANTOS, et.al., 2018).

Pode-se perceber que as ações em nome do desenvolvimento humano provocaram o aumento da poluição ambiental, tornando difícil o seu combate e acarretando a biodegradação, uma vez que, o desenvolvimento e a degradação caminharam de forma simultânea. Esse cenário mostra-se antagônico à busca do crescimento econômico em concordância com a proteção do meio ambiente que visa assegurar a sobrevivência das futuras gerações, conforme propõe o relevante conceito de desenvolvimento sustentável (SANTOS, et. al., 2018).

Em contraponto a situação mencionada anteriormente, para reduzir os danos ocasionados ao longo das últimas décadas, houveram diversas iniciativas como por exemplo, encontros e conferências globais, tratados e acordos o quais foram assinados pela maioria dos países, tendo como destaque internacional a Conferência de Estocolmo em 1972 na Suécia, que ficou reconhecida como um marco histórico por problematizar a necessidade de melhorar as relações do homem com o meio ambiente, propondo equilíbrio entre o desenvolvimento econômico e a redução da degradação ambiental (HOELLER; FAGUNDES, 2020), mais a frente, na década de 80 o Relatório Brundtland (1987) e na década de 90 na cidade do Rio de Janeiro, aquela que ficou conhecida como a Rio 92, onde foi realizada a Conferência das Nações Unidas para o Ambiente e Desenvolvimento.

O conceito de Desenvolvimento Sustentável, adotado na Rio 92, envolve a preservação ambiental, inclusão social e crescimento econômico (SILVA; et al. 2016). Ainda pode-se destacar que foram fechados acordos internacionais em conferências, como a Convenção do Clima, a Declaração do Rio, a Convenção da Biodiversidade e a Agenda 21 (ARAUJO; CARVALHO; CASTRO, 2013)

Infelizmente atualmente são poucas as empresas que adotam um sistema adequado de gestão ambiental, muito disso se deve a falsa crença que sustentabilidade acarreta elevação de custo. Diante das condições de desenvolvimento descritas, levando-se em consideração o mau uso do meio ambiente é importante à busca e a implementação de uma mudança de mentalidade, ou cultura, nas relações com o meio ambiente, com o objetivo de buscar e agregar novos valores éticos na relação com a natureza e que essa, a natureza, como cita Pereira (2012), seja vista como um meio de sobrevivência para as espécies que vivem no planeta, e não apenas como uma fonte de geração de lucros. 


\section{Ciências ambientais e o viés da interdisciplinaridade: a Educação Ambiental}

Para resolver a problemática social do crescimento humano e, do uso dos recursos naturais por ele explorado, é necessário ir além do pensamento de que cada área especializada da ciência não tem interação com as outras. Como ressalta Alves (2004) a ciência não é um órgão novo. Ela é uma hipertrofia de capacidades que todos têm, utilizada de forma disciplinada e ordenada.

Para compreender a relação entre as Ciências Ambientais e os anseios de transitar por um ambiente interdisciplinar, é necessário compreender alguns conceitos. Os conceitos que se destacam são as variações da interdisciplinaridade, entre elas a multidisciplinaridade, interdisciplinaridade e transdisciplinaridade, destacadas por Bicalho e Oliveira (2011), tais variações assumiram diversos significados ao longo do tempo, porém, mantém em comum aproximação acadêmico-científica permitindo o surgimento de vários ramos ou especializações aplicadas à ciência, no século XIX e durante o século $X X$.

A inter-relação dos campos das ciências e suas articulações compreendem processos de prática e conhecimento. Assim, a interdisciplinaridade de acordo com Leff (2008) propicia uma conexão com os diversos campos do conhecimento, independente da disciplina, protagonizando o desenvolvimento para os atores sociais e das instituições. Isso, através da necessidade de unir os fragmentos de conhecimento para encaminhar-se para o desenvolvimento sustentável.

Em termos gerais, o meio ambiente representa a interação da sociedade com todos os ecossistemas (fatores bióticos e abióticos). Além disso, representa uma realidade histórico-social, plurifacetada e interdisciplinar (COIMBRA, 2000).

Nas Ciências Ambientais a interdisciplinaridade surge no anseio de reunir as ciências sociais com as ciências naturais, tecnológicas e exatas, propondo diretamente melhorar a sociedade (DRUMMOND; SCHROEDER, 1998). Nesse sentido, considerando a realidade brasileira, Philippi Jr. (2000) destaca os esforços da comunidade da área das Ciências Ambientais e das articulações com as demais áreas do conhecimento, para que as Ciências Ambientais se integrassem ao sistema nacional da ciência e tecnologia.

Para um melhor entendimento pode-se fazer uma rápida cronologia que explica os passos que levaram a isso. Assim, pode-se dizer que um ano após a Conferência de Estocolmo, ocorrida em 1972, para atendimento às recomendações internacionais, instituiu-se a Secretaria Especial do Meio Ambiente (SEMA). Esta tinha, como uma de suas atribuições, a educação dos brasileiros para uso adequado dos recursos naturais, para a conservação do meio ambiente (DE SOUZA DIMAS et al., 2021). E na sequência, quase uma 
década depois foi criada a Política Nacional de Meio Ambiente (PNMA) no ano de 1981, tendo como objetivo a preservação da qualidade ambiental, visando assegurar, condições do desenvolvimento socioeconômico, aos interesses da segurança nacional e à proteção da dignidade da vida humana (SEIFFERT, 2011). E em 1988 com a promulgação da Constituição Federal que aborda em um de seus capítulos, de modo específico, objetivo e global a proteção ao meio ambiente, tendo um capítulo específico para regras sobre o meio ambiente (BRASIL, 2006).

Seguindo esse contexto, em 1999 é promulgada a Lei no 9.795 que trata da Política Nacional de Educação Ambiental (PNEA) que orienta o tratamento interdisciplinar e transversal da questão ambiental, em todos os níveis da educação formal. Nesse ponto é importante destacar que para Santos e Gould (2018) a Educação Ambiental e definida como aquela que influencia a maneira como as pessoas entendem, pensam e conectam-se ao mundo ao seu redor.

Pensamento alinhado ao da PNEA que reconhece em seu texto a interdependência entre os seres humanos e a natureza, expresso em seu Artigo 10:

Entendem-se por Educação Ambiental os processos por meio dos quais o indivíduo e a coletividade constroem valores sociais, conhecimentos, habilidades, atitudes e competências voltadas para a conservação do meio ambiente, bem de uso comum do povo, essencial à sadia qualidade de vida e sua sustentabilidade (BRASIL, 1999).

Nesse mesmo sentido, a Educação Ambiental, para Uhmann e Vorpagel (2018) é um tema transversal fundamental na sensibilização para a tomada de consciência, essa que precisamos adquirir e melhorar a fim de construirmos uma sociedade sustentável, considerando que a crise ambiental e as consequentes mudanças climáticas, decorrem principalmente dos meios e dos modos de produção.

Corroborando com isso, está definido na PNEA, que a Educação Ambiental, como parte do processo educativo mais amplo, deve ser pata todos, pois todos têm direito a ter acesso a ela e cabe ao poder público definir políticas públicas que incorporem a dimensão ambiental, promovendo a Educação Ambiental em todos os níveis de ensino. Neste contexto, estas políticas públicas devem permitir um engajamento crítico e uma educação reflexiva, levando em consideração os diversos aspectos relacionados às mudanças climáticas entre elas: os socioeconômicos, os ambientais, os políticos, os científicos, os culturais e os saberes locais (BRASIL, 2013).

Nesse sentido, para as Ciências Ambientais a Educação Ambiental pode ser um importante instrumento de enfrentamento dos problemas socioambientais, 
Em Educação Ambiental, ciência e formação crítica precisam se relacionar de modo a compreendermos sob que condições o saber científico se desenvolveu e a favor de que e de quem, nos apropriando da base instrumental reflexiva necessária para a educação, para alteração objetiva das condições de vida da população e reversão do processo de degradação e exploração das demais espécies e da natureza como um todo, rompendo com dogmas e obstáculos à liberdade humana (LOUREIRO, 2012, p.30).

Seguindo na perspectiva do PNEA, as Ciências Ambientais passam a ser tratadas de modo interdisciplinar na academia. Nesse contexto surge com naturalidade a interdisciplinaridade, como concepção, processo e forma de produzir conhecimentos, impulsionada pela necessidade de interligar saberes e ampliar a cooperação técnico-científica, algo que docentes e pesquisadores que atuam de modo interdisciplinar passam a incorporar em suas práticas (PHILIPPI et al., 2013), o que segundo Santana et al. (2017), por outro lado, anteriormente à década de 80 , as publicações realizadas com a temática das Ciências Ambientais segregam o homem e o meio ambiente. $O$ autor afirma que depois que essa fragmentação foi desfeita o número de publicações cresceu.

Ainda em relação às publicações na área das Ciências Ambientais, dois eventos históricos se tornaram importante para a temática, registrados por Pott; Estrela (2017) sendo elas: Cúpula da Terra - Rio 92 em 1992 e a Conferência das Partes 3 (COP 3) no Japão em 1997. Segundo o autor, foi constatado que as informações sobre os temas dos eventos eram quase extintas, abrindo caminhos para as editoras despertarem o interesse na produção literária de conteúdos voltados para as Ciências Ambientais.

Os autores Philippi Jr. et al. (2000) destacam que o espaço central ocupado pela ciência e tecnologia propõe que ambas sirvam de instrumento para o desenvolvimento sustentável, contribuindo, através de propostas de inserção ambiental, como a política e a administração. Esses caminhos tornam a sociedade cada vez mais protagonista das mudanças propostas, caminhando em busca do desenvolvimento sustentável.

As publicações e logicamente a pesquisa que atribui suporte a essas publicações está alicerçada nas universidades e essas nos cursos de pósgraduação, onde para Ferreira; Monteira (2018) é o principal meio da produção científica do país. O autor destaque que está ocorre em virtude da maioria dos pesquisadores e dos recursos de financiamento à pesquisa estar vinculada a programas de pós-graduação.

Do exposto pode-se perceber que o direcionamento do tema Ciências Ambientais requer, sem dúvida nenhuma, uma abordagem que seja o mais abrangente possível, perpassando pela multidisciplinaridade, interdisciplinaridade e chegando à transdisciplinaridade. Essa última entendida 
como aquela que "guia-se por um pensar que, ao invés de valorizar a simplificação, valoriza a complexidade, a tessitura articulada dos saberes e dos conhecimentos" (DE PAULA, et al., 2016). Em outras palavras, propõem a valorização e a legitimação das diferentes áreas dos campos científicos e do "não científico".

E por outro lado, logicamente não deve estar confinada aos muros acadêmicos, de onde saem às produções cientificas, mas sim ser um assunto transversal, formalmente tratado como Educação Ambiental em todos os níveis da formação do cidadão, como descrito no PNEA. Pode ser essa considerada uma utopia, mas que por outro lado, como afirmam De Sousa e De Pinho (2017) romperia, com a lógica hierarquizante da racionalidade fundamentada no paradigma da ciência moderna, que segrega, marginaliza e verticaliza o conhecimento.

\section{Considerações finais}

Visando contemplar o amplo espectro que a Ciência Ambiental denota na relação do homem com meio ambiente, este artigo buscou apresentar que no processo de sobrevivência humana, enquanto sociedade, que o uso dos recursos naturais trouxe transformações ao meio ambiente, pelo uso desses na manufatura de bens e serviços. E que por outro lado, seu uso sem o devido cuidado de preservação para as futuras gerações, tem se mostrado antagônico aos conceitos de sustentabilidade e desenvolvimento sustentável, importantes para o tema Ciências Ambientais. Embora esses termos segundo Feil e Schreiber (2017), muito utilizados na literatura científica, no setor privado e nas políticas públicas, ainda não possuem consenso em termos de conceito.

Em contexto, a sociedade se desenvolveu na perspectiva de explorar o meio, sem se preocupar com a escassez dos produtos advindos da natureza. No âmbito global, marcados pela Revolução Industrial, iniciada na Inglaterra em meados do século XVIII, o que mais tarde, acarretou preocupações que ecoaram a nível global, e que resultaram em acordos internacionais, onde os países se comprometem com a proteção, ainda que pontual, do meio ambiente. As Ciências Ambientais tornam-se o ponto de convergência para o debate e a formação do pensamento crítico, no Brasil, principalmente, a partir da implantação do PNEA, tendo como base a necessidade de compreender o mundo e buscar ferramentas para o viver melhor e atender as necessidades do mundo moderno e nesse momento entra a Educação Ambiental como ferramenta interdisciplinar para formação de uma consciência ambiental.

As Ciências Ambientais surgem, em todo esse contexto, para abrandar e direcionar melhores caminhos para o uso dos recursos naturais, através do desenvolvimento de estudos e aplicações de tecnologias, tendo como foco o conceito de sustentabilidade, que deveria atender também além da preservação ambiental a inclusão social e o crescimento econômico. Pois como afirma Rosa et al. (2021), a compreensão deque somos dotados de liberdade, 
mas responsáveis por nossas ações, presente em nossa Carta Magna, e de que estamos inseridos no meio ambiente do qual somos dependentes, denota Responsabilidade Social

Reforçando aqui o desenvolvimento sustentável como um processo que integra estratégias que harmonizem as necessidades humanas a um plano de sustentabilidade que não afete, longo do tempo, de modo irreversível, o complexo sistema chamado natureza.

Contudo, a ciência consiste na busca do conhecimento de situaçõesproblema. No que diz respeito às Ciências Ambientais, é necessário identificar e ter clareza dos problemas a serem enfrentados, para que dessa forma, obtenha-se uma análise precisa, em seu escopo de interdisciplinaridade, e que assim se consiga almejar uma solução pacífica e harmônica na relação homem versos meio ambiente.

\section{Referências}

ALTVATER, E. O preço da riqueza. Tradução de Wolfong Leo Maar. São Paulo: UNESP, 1995. $333 \mathrm{p}$.

ALVES, R. Filosofia da ciência: introdução ao jogo e suas regras. Edições Loyola, 2004.

ANTUNES, R. A dialética do trabalho: escritos de Marx e Engels. Editora Expressão Popular. 2. ed. São Paulo, 2005. 200 p.

ARAUJO, G. J. F.; CARVALHO, C. M.; CASTRO, V. A importância da prática da sustentabilidade e de seus indicadores para implementação e consolidação de vantagens competitiva nas organizações empresariais. Periódico Eletrônico Fórum Ambiental da Alta Paulista. Anais do IX Fórum Ambiental da Alta $\begin{array}{lllll}\text { Paulista, } & \text { v. } & 913 .\end{array}$ DOI:http://dx.doi.org/10.17271/198008279102013494

BARBOSA, G. S.; DRACH, P. R.; CORBELLA, O. D. A Conceptual Review of the Terms Sustainable Development and Sustainability. International Journal of Social Sciences, v. III, n. 2, p.1-15, 2014.

BICALHO, L. M; OLIVEIRA, M. A teoria e a prática da interdisciplinaridade em Ciência da Informação. Perspectivas em Ciência da Informação, v. 16, n. 3, p. 47-74, jul. 2011.

BRASIL. Política Nacional de Educação Ambiental. Lei № 9795/1999 de 27 Abril de 1999. Disponível em: <http://www.planalto.gov.br/ccivil 03/leis/19795.htm>. Acesso em: 20 jan. 2021.

CAVALCANTI, C; et al. Desenvolvimento e natureza: estudos para uma sociedade sustentável. INPSO/FUNDAJ, Instituto de Pesquisas Sociais, Fundação Joaquim Nabuco, Brasil. p. 262. 1994. 
CIDREIRA-NETO, I. R. G.; RODRIGUES, G. G. Relação homem-natureza e os limites para o desenvolvimento sustentável. Revista Movimentos Sociais e Dinâmicas Espaciais, v. 6, n. 2, p. 142-156, 2017.

COIMBRA, J. A. A. Considerações sobre a interdisciplinaridade. In: SARDENBERG, R. M.; CAVALHEIRO, E. A. e FONSCECA, A. P Interdisciplinaridade em ciências ambientais. São Paulo: Signos Editora, p. $52-70,2000$

COMISSÃO MUNDIAL DE MEIO AMBIENTE E DESENVOLVIMENTO. Nosso Futuro Comum. Rio de Janeiro: FGV, 1987.

DA ROSA, G. M. et al. Aspectos relativos às tecnologias empregadas na geração de energias limpas. Revista Gestão \& Sustentabilidade Ambiental, v. 9, n. 3, p. 127-149, 2020.

DA ROSA, G. M.; DA SILVA, F. R.; DA COSTA JÚNIOR, J. A. Ações antrópicas e exploração dos recursos ambientais no meio rural, no norte do RS: questões históricas, culturais e desafios para projetar novas atitudes. Research, Society and Development, v. 10, n. 10, p. e463101019245e463101019245, 2021.

DA ROSA, G. M.; DA SILVA, F. R.; FLACH, K. A. Educação Ambiental na educação escolar e a Responsabilidade Social: desafios e possibilidades nas questões ambientais. Revista Brasileira de Educação Ambiental, v. 16, n. 5, p. 411-430, 2021.

DE PAULA, M. V. G.; SUANNO, J. H. Transdisciplinaridade e educação física escolar: reflexões para o desenvolvimento humano. Revista Polyphonía, v. 27, n. 1, p. 437-453, 2016. DOI: https://doi.org/10.5216/rp.v27i1.42323

DE SOUSA, J. G.; DE PINHO, M. J.. Interdisciplinaridade e transdisciplinaridade como fundamentos na ação pedagógica: aproximações teórico-conceituais. Revista Signos, v. 38, n. 2, p. 93-110, 2017.

DE SOUZA DIMAS, M.; NOVAES, A. M. P.; AVELAR, K. E. S.. O ensino da Educação Ambiental: desafios e perspectivas. Revista Brasileira De Educação Ambiental, v. 16, n. 2, p. 501-512, 2021.

DELARIVA, R. L.; AGOSTINHO, A. A. Introdução de espécies: uma síntese comentada. Rev. Acta Scientiarum. Biological Sciences. v 21, p. 255-262, 1999.

DRUMMOND, J. A.; SCHROEDER, A. Programas de Pós-Graduação em Ciências Ambientais e similares no Brasil - uma listagem preliminar. Rev. Ambiente \& Sociedade. Campinas: NEPAM, ํo. 2, p.139-149,1998.

FEIL, A. A.; SCHREIBER, D. Sustentabilidade e desenvolvimento sustentável: desvendando as sobreposições e alcances de seus significados. Cadernos Ebape. BR, v. 15, n. 3, p. 667-681, 2017. 
FERREIRA, J. H. M.; MONTEIRA, M. do S. L. As ciências ambientais e a interdisciplinariedade no âmbito da pesquisa e pós-graduação no Brasil. Educação Ambiental em Ação, v. 17, n. 64, 2018.

GIRÃO, O.; CORREA, AC de B. A contribuição da geomorfologia para o planejamento da ocupação de novas áreas. Revista de Geografia, Recife, v. 21, n. 2, p. 36-58, 2004.

GUERRA, A. J. T.; MARÇAL, M. S. (Org.). Geomorfologia ambiental. 3a․ ed. Rio de Janeiro: Bertrand Brasil, 2010, p.189.

HOELLER, S.; FAGUNDES, M.. Educação Ambiental: um caminho possível para a construção de um projeto societário sustentável?. Revista Brasileira De Educação Ambiental, v. 15, n. 5, p. 213-229, 2020.

LAYRARGUES, P. P. Educação para a gestão ambiental: a cidadania no enfrentamento político dos conflitos socioambientais. In: LOUREIRO, C. F. B. (Org.). Sociedade e meio ambiente: a Educação Ambiental em debate. São Paulo: Cortez, p. 87-155, 2000.

LEAL, G. C. S. G.; FARIAS, M. S. S.; ARAúJO, A. F. O processo de industrialização e seus impactos no meio ambiente urbano. Revista Eletrônica. p.1-11, 2008.

LEFF, E.; Saber Ambiental: Sustentabilidade, racionalidade, complexidade, poder. Tradução: Lucia Mathlde Endlich Orth. Ed. Vozes, Petrópolis, RJ, 2001.

LOPES, D. O Desenvolvimento Insustentável: Capitalismo e Natureza. III Simpósio Mineiro de Assistentes Sociais, 2011. Disponível em: http://www.cress-

mg.org.br/arquivos/simposio/O\%20DESENVOLVIMENTO\%20INSUSTENT\%C 3\%81VEL \%20CAPITALISMO\%20E\%20NATUREZA.pdf. Acessado em 15 de out 2020.

MEADOWS, D. H., MEADOWS, D. L., RANDERS, J., BEHRENS, W. W.. Limites do Crescimento: Um Relatório para o Projeto do Clube de Roma sobre o Dilema da Humanidade. Perspectiva, São Paulo. Tradução Inês M. F. Litto. 1972. p. 203.

MELARA, E.; CARDOZO, D. A Questão Ambiental e os Impasses da Ciência Geográfica: Uma Reflexão Preliminar. In: Revista Digital Simonsen, № 7, Ago. 2017.

MIKHAILOVA, I. Sustentabilidade: evolução dos conceitos teóricos e os problemas da mensuração prática. Economia e Desenvolvimento, n. 16, p. 22-41. 2004.

MILLER, G. Tyler. Ciência Ambiental. Tradução All Tasks. 11a ed. norte americana. São Paulo: Cencage Lerning, 2008. Disponível em https://issuu.com/cengagebrasil/docs/ciencia ambiental livreto. Acessado em 21 Nov. 2020. 
MINAYO, M. C. de S.; DESLANDES, S. F.; GOMES, R. Pesquisa social: teoria, método e criatividade. In: Pesquisa social: teoria, método e criatividade. 2002. p. $95 . \quad$ Disponível em: $<$ https://wp.ufpel.edu.br/franciscovargas/files/2012/11/pesquisa-social.pdf>. Acessado em 20 de Jan de 2021

OLIVEIRA, A. M. S. Relação Homem/Natureza no Modo de Produção Capitalista. Rev. Pegada, v.3, 2002.

OMS (Organização Mundial da Saúde). 7 milhões de mortes prematuras anualmente relacionadas à poluição do ar. (2014). Disponível em: $<$ http://www.who.int/mediacentre/news/releases/2014/air-pollution/en/>.

Acessado em 20 de Jan. 2021.

PASSOS, T. S.; OLIVEIRA, C. C. C. Relação homem-natureza e seus impactos no ambiente, saúde e sociedade: uma problemática interdisciplinar. Anais do 8을 Encontro Internacional de Formação de Professores, v. 9, n.1, 2016. Disponível em <https://eventos.set.edu.br/enfope/article/view/2229/754>. Acessado em Nov. 23 de 2020.

PEREIRA, J. I. Sustentabilidade: diferentes perspectivas, um objectivo comum. Economia Global e Gestão, Lisboa, v. 14, n. 1, p.115-126, abr. 2009.

PEREIRA, S. S. Meio ambiente, impacto ambiental e desenvolvimento sustentável: conceituações teóricas sobre o despertar da Consciência ambiental. Revista de Administração, Contabilidade e Sustentabilidade, v. 2, no-4, p.35-57. 2012.

PHILIPPI JR., A. et al. Uma Visão Atual e Futura da Interdisciplinaridade em C\&T Ambiental. In: SARDENBERG, R. M.; CAVALHEIRO, E. A. e FONSCECA, A. P. Interdisciplinaridade em ciências ambientais. Editora Signos, p. 269279, 2000.

PHILIPPI JR, A. et al. Desenvolvimento sustentável, interdisciplinaridade e Ciências Ambientais. Revista Brasileira de Pós-Graduação, v. 10, n. 21, 2013.

POTT, C. M.; ESTRELA, C. C. Histórico ambiental: desastres ambientais e o despertar de um novo pensamento. Dilemas Ambientais e Fronteiras do Conhecimento II. São Paulo, p.271-283, 2017. Disponível em: $<$ https://www.scielo.br/scielo.php?script=sci arttext\&pid=S010340142017000100271>. Acessado em 20 Jan. 2021.

POTT, C. M.; ESTRELA, C. C. Histórico ambiental: desastres ambientais e o despertar de um novo pensamento. Estudos avançados, v. 31, n. 89, p. 271283, 2017.

ROHDE, G. M. Epistemologia Ambiental: uma abordagem filosófica-cientifica sobre a efetuação humana alopoética. 2 ed. Porto Alegre: EDIPUCRS, v.1, p. 407, 1996. Disponível em <https://www.scielo.br/pdf/er/n27/a03n27.pdf>. Acessado em 24 de Ago. de 2020 
ROOS, A.; BECKER, E.L.S. Educação Ambiental e Sustentabilidade. Revista Eletrônica em Gestão, Educação e Tecnologia Ambiental, REGET/UFSM, v. 5, n. 5, p. 857-866, 2012.

SANTANA, O. A. et al. Ensino de Ciências Ambientais rumo à profissionalização: uma análise cientométrica. Revista Brasileira de PósGraduação. v. 14. p. 1-17. 2017.

SANTO, N. B.; GOULD, R. K.. Can relational values be developed and changed? Investigating relational values in the environmental education literature. Science Direct. Toronto, v. 35, p.124-131, dez. 2018. DOI: https://doi.org/10.1016/j.cosust.2018.10.019.

SANTOS, J. S.; LEITE, C. C. C.; VIANA, J. C. C.; SANTOS, A. R.; FERNANDES, M. M.; ABREU, V. S.; NASCIMENTO, T. P.; SANTOS, L. S.; FERNANDES, M. R. M.; SILVA, G. F.; MENDONÇA, A.R. Delimitation of ecological corridors in the Brazilian Atlantic Forest. Ecological Indicators, v. 88, p.414-424. 2018.

SEIFFERT, M. E. B. Gestão ambiental: instrumento, esferas de ação e Educação Ambiental. 2 ed. São Paulo: Atlas, 2011, p. 493.

SEVERINO, A. J. Metodologia do trabalho científico. 23a. ed. rev. e atualizada. São Paulo: Cortez, 2013.

SILVA, J. K. L.; SIENA, O. As influências do compromisso ideológico e das teorias de base para concepções ambientais da Associação de Defesa Etnoambiental Kanindé. Revista de Gestão. v. 23, p. 338-348, 2016.

STEPANYAN, K.; LITTLEJOHN, A.; MARGARYAN, A. Sustainable e-Learning: Toward a Coherent Body of Knowledge. Educational Technology \& Society, v. 16, n. 2, p. 91-102, 2013.

UBALDO, B. M. et al., Evolução histórica do processo de ruptura entre o homem e a natureza. Revista Interdisciplinar em Cultura e Sociedade, v. 4, n. Espec, p. 383-393, 2019.

UHMANN, R. I. M.; VORPAGEL, F. S. Educação Ambiental em Foco no Ensino Básico. Pesquisa em Educação Ambiental. v. 13, n. 2, p. 53-68, 2018.

WALGENBACH, W.; MARTINS, R, P.; BARBOSA, F. A. R.; NAVEGANTES, R. Modos Operativos de Integração Disciplinar nas Ciências Ambientais. In: SARDENBERG, R. M.; CAVALHEIRO, E. A. e FONSCECA, A. P. Interdisciplinaridade em ciências ambientais. Editora Signos, p. 211-245, 2000. 